\title{
Permanent pacemaker implantation after cardiac transplantation: extra cost of a conservative policy
}

\author{
Nicola D Holt, Gareth Parry, Margaret M Tynan, John H Dark, Janet M McComb
}

\begin{abstract}
Objective-To determine the costs of a change in permanent pacemaker implantation policy to later implantation (day 21+) after cardiac transplantation.

Design-Retrospective review of patient records including duration of temporary pacing, time of permanent pacemaker implantation, and length of hospital stay for every patient surviving $\geqslant 14$ days from November 1990 to August 1995 (period 2) and for all patients in whom permanent pacemakers were implanted between May 1985 and November 1990 (period 1).
\end{abstract}

Setting-Supra-regional cardiopulmonary transplant unit.

Patients-335 consecutive adult cardiac transplant recipients at Freeman Hospital between May 1985 and August 1995.

Main outcome measures-The cost of the policy change was calculated by subtraction of the overall saving in pacemaker implantations from the overall cost of the extra inpatient stay in period 2 due to delayed implantation.

Results-Mean inpatient stay per patient following cardiac transplantation of permanent pacemaker recipients in period 1 was 13.8 days compared with 23.9 days in period $2(P<0.001)$. The cost of this extended hospital stay is $£ 60095$. Had the implantation policy not been changed, a further seven patients would have received a permanent pacemaker in period 2. A saving in pacemaker hardware of $£ 16275$ was made. Overall, however, the new permanent pacemaker implantation policy increased expenditure by $£ 43820$, assuming that permanent pacemaker implantation was the only reason for the extended hospital stay.

Conclusion-The change in policy from early to later permanent pacemaker implantation has markedly increased expenditure.

(Heart 1996;76:439-441)

Keywords: audit; pacemakers; cardiac transplantation

Up to a third of human orthotopic cardiac transplant recipients have permanent pace- makers implanted because of bradyarrhythmias. ${ }^{1-6}$ Before November 1990, permanent pacemakers were implanted at our centre as early as day 8 after transplantation in patients with a resting heart rate below 70 beats per minute. Review of our practice showed that no patients with permanent pacemakers implanted before day 16 post transplantation continued to pace long term. ${ }^{5}$ We therefore changed our policy to delay implantation, such that only recipients with bradyarrhythmias that persisted at or after day 21 received a permanent pacemaker. We reviewed the costs of this new policy in September 1995.

\section{Methods}

We have previously described the temporary epicardial and permanent pacing policy in orthotopic cardiac transplant recipients at our centre. ${ }^{5-7}$

The two different policy periods were identified as periods 1 and 2:

Period 1 (May 1985 to November 1990) Permanent pacemaker implantation between days 8 and 20 after cardiac transplantation.

Period 2 (December 1990 to August 1995) Permanent pacemaker implantation on or after day 21 after cardiac transplantation

Data collected for those receiving permanent pacemakers in both periods included inpatient bed days from transplantation to implantation, indication for pacing, type of pulse generator inserted, and complications arising from implantation. In addition we noted the number of days temporary epicardial pacing was required for all recipients who survived more than 14 days in period 2 .

Mean inpatient stay for those patients with permanent pacemaker implantation was calculated for each period. The number of patients spared permanent pacemaker implantation as a result of the change in policy was taken as those patients paced via temporary epicardial wires at day 16 who did not subsequently receive a permanent pacemaker.

All costs were based on 1995 figures. The mean cost of a permanent pacemaker system for each period was based on the mean cost of the systems implanted in these patients during the specified period and included generators, leads, theatre time, and mean cost attributable to lead replacement/repositioning in that period. 
Table 1 Permanent pacemaker implantation

\begin{tabular}{lcc}
\hline & Period 1 & Period 2 \\
\hline $\begin{array}{l}\text { Number of cardiac transplants } \\
\text { Number of patients with permanent }\end{array}$ & 152 & 180 \\
pacemaker implantations & $16(10.5 \%)$ & $14(7 \cdot 8 \%)$ \\
Mean (SD) time to implantation (days) & $13 \cdot 8(3 \cdot 9)^{\star}$ & $23.9(5 \cdot 8)^{\star}$ \\
\hline$\star \mathrm{P}<0.001$ &
\end{tabular}

The estimated saving in permanent pacemaker implantations in period 2 was calculated by multiplying the number of patients spared pacemaker implantation by the mean cost of a pacemaker system in period 2 . The estimated cost of the increased bed occupancy owing to the delay in permanent pacing was calculated by multiplying the number of patients with pacemaker implantation in period 2 by the difference in mean bed day occupancy between the two periods and then by the mean cost of inpatient stay per patient per day in period 2.

Thus the cost of the change in permanent pacemaker implantation policy was calculated by subtraction of the estimated cost of the increased bed occupancy from the estimated saving in permanent pacemaker system implantations.

STATISTICAL ANALYSIS

Mean time to implantation and mean cost of permanent pacemaker systems were compared between the two periods using Student's $t$ test. Modes of pacing in the two periods were compared using Fisher's exact test.

\section{Results}

Three hundred and thirty five consecutive adult orthotopic cardiac transplants were performed in adults from May 1985 to the end of August 1995. Thirty one permanent pacemakers were implanted in 30 patients (9\%) within one month of cardiac transplantation. Three patients had permanent pacemakers implanted after the first month post-transplantation and have been excluded from analysis. Details of number of cardiac transplants, number of patients with permanent pacemaker implantations, and mean time to implantation for the two time periods are given in table 1 .

There were three lead displacements-that is, $8 \%$ of leads implanted. Two ventricular leads were displaced during routine cardiac biopsy one week after implantation (both in period 1). Both were repositioned. One atrial lead in a DDDR system displaced spontaneously one week after pacemaker implantation and was replaced (period 2). There were

Table 2 Cost of change in implantation policy in period 2

\begin{tabular}{llll}
\hline $\begin{array}{l}\text { (A) Estimated cost of increased } \\
\text { bed occupancy }\end{array}$ & \multicolumn{3}{c}{$\begin{array}{l}\text { (B) Estimated saving in permanent } \\
\text { pacemaker systems }\end{array}$} \\
\hline $\begin{array}{l}\text { Corrected mean inpatient bed } \\
\text { cost per patient per day }\end{array}$ & $£ 425$ & $\begin{array}{c}\text { Mean cost of pacemaker } \\
\text { implantation in period 2 }\end{array}$ & $£ 2325$ \\
$\begin{array}{c}\text { Number of patients with } \\
\text { permanent pacemakers } \\
\text { implanted in period 2 }\end{array}$ & 14 & $\begin{array}{c}\text { Number of patients spared } \\
\text { pacemaker implantation } \\
\text { in period 2 }\end{array}$ & 7 \\
$\begin{array}{l}\text { Mean delay in pacemaker } \\
\text { implantation in period 2 (days) }\end{array}$ & $10 \cdot 1$ & $£ 60095$ & Estimated saving \\
$\begin{array}{l}\text { Estimated extra cost } \\
\text { Cost of change in implantation policy }=£ 60095-£ 16275=£ 43820 .\end{array}$ & $£ 16275$ \\
\hline
\end{tabular}

Table 3 Types and numbers of pulse generators implanted

\begin{tabular}{llc}
\hline Type of pulse generator & Period 1 & Period 2 \\
\hline VVI & $8^{\star}$ & 0 \\
VVIR & 7 & 1 \\
AAIR & 0 & 8 \\
DDD & $1^{\star}$ & 1 \\
DDDR & 1 & 4 \\
Total & $17^{\star}$ & 14 \\
$\begin{array}{l}\text { Mean cost of permanent } \\
\text { pacemaker system }\end{array}$ & $£ 1737 \dagger$ & $£ 2325 \dagger$ \\
\hline
\end{tabular}

${ }^{\star} 1$ recipient had a generator change from VVI to DDD due to pacemaker syndrome.

$\dagger \mathrm{P}=0.02$.

no other complications of pacemaker implantation.

Compared with period 1, pacemaker implantation was significantly delayed by a mean of 10.1 days during period 2 ( $\mathrm{P}<$ $0.001)$. Mean cyclosporin dose per patient was $250 \mathrm{mg}$ twice a day. Bed occupancy cost per patient per day on the transplant ward was $£ 440$. The cost of cyclosporin was deducted because it was expensive and patients received it whether they were inpatients or outpatients. The corrected mean cost of inpatient stay per patient per day with cyclosporin cost deducted was $£ 425$. The estimated cost of increased bed occupancy in period 2 is calculated in table 2.

Seven patients in period 2 were paced via temporary epicardial wires for more than 16 days post-transplantation and thus potentially would have undergone permanent pacemaker implantation if the policy of period 1 had not been changed. The estimated saving in permanent pacemaker systems in period 2 is calculated in table 2 . The change in implantation policy therefore increased expenditure by $£ 43820$.

The mode of permanent pacing and mean cost of permanent pacemaker systems in the two periods are detailed in table 3 . There were significantly more atrially based pacemakers in period 2 than in period $1(2 / 16 v 13 / 14$, period $1 v$ period $2, \mathrm{P}<0.001)$. There were significantly more rate responsive pacemakers in period 2 than in period $1(8 / 16 v 13 / 14$, period $1 v$ period $2, \mathrm{P}=0.02$ ). These two changes led to a mean increase in pacemaker costs of about $£ 600$ per unit in period $2(P=0.02)$.

\section{Discussion}

There was a trend to reduce the number of permanent pacemakers implanted $(10.5 \%$ to $7 \cdot 8 \%)$. Seven patients were successfully spared implantation. If policy 1 had been continued throughout period $2,21 / 180(11 \cdot 7 \%)$ patients would have received pacemakers. We have already described the clinical outcome of a change in permanent pacemaker implantation policy after cardiac transplantation in our centre. ${ }^{7}$

This study showed that a more conservative policy has increased expenditure by $£ 43820$ or about $£ 6250$ per pacemaker saved, assuming permanent pacemaker implantation was the only reason for the extended hospital stay.

The delay in implanting permanent pacemakers, however, spared seven patients the 
potential morbidity and mortality of implantation.

There were changes in the mode of the permanent pacemakers implanted between the two periods. These changes were unrelated to the review and probably reflect the British Pacing and Electrophysiology Group recommendations ${ }^{8}$ and a change in permanent pacing policy in our cardiology department. ${ }^{910}$ There was a significant increase both in atrially based pacing and in rate-responsive pacing. It is yet to be shown which mode of pacing is best in cardiac transplant recipients. The change to atrially based pacing is physiologically sound though its value is not proven in this population. We have, however, demonstrated that donor atrial and atrio-ventricular sequential pacing result in significantly better cardiac outputs than right ventricular pacing at rest. ${ }^{11}$ Because transplant recipients return to an active lifestyle, a rate responsive mode of pacing has been advocated because of the results of studies in the non-transplant population. ${ }^{8}$ This mode of pacing may not be applicable to the transplant population, however. Cardiac transplant recipients with sinus node dysfunction and without demonstrate similar chronotropic responses to exercise without limitation of exercise capacity, with both groups showing chronotropic incompetence because of autonomic denervation. ${ }^{12}$ There is no evidence that rate responsive pacemakers would therefore be of benefit to recipients requiring permanent pacemakers for bradycardias. We have shown in one patient that exercise times on a standard treadmill test were similar in both VVI and VVIR modes. ${ }^{6}$

\section{LIMITATIONS OF THE STUDY}

The retrospective nature of this study meant that patients spared pacemaker implantation were identified by assuming that those patients paced with temporary epicardial wires at day 16 post-transplantation would have received a permanent system had the old protocol been followed. This has inherent problems in that patients may have been temporarily paced to a higher heart rate despite a resting heart rate of 70 beats per minute to improve cardiac output in situations such as renal impairment or fluid retention.
The true cost per day for patients awaiting implantation is probably less than the cost given here because the patients did not necessarily require high dependency care that is given, and therefore costed, on the transplant ward.

\section{CONCLUSIONS}

A blanket policy for the timing of permanent pacemaker implantation after cardiac transplantation has saved seven implantations. This small reduction in pacemaker implantations was achieved at substantial apparent extra cost, mainly due to the increase in hospital bed days. The increased expenditure should be balanced with the theoretical morbidity benefits to those spared permanent pacemaker implantation.

1 Miyamoto Y, Curtiss EI, Kormos RL, Armitage JM, Hardesty RL, Griffith BP. Bradyarrhythmias after heart transplantation. Circulation 1990;82(suppl IV):313-7.

2 Loria K, Salinger M, McDonough T, Frohlich T, Arentzen C. Activitrax AAIR pacing for sinus node dysfunction after orthotopic heart transplantation: an initial report. $f$ after orthotopic heart transplan

3 Heinz G, Ohner T, Laufer G, Bossinger H, Gasic S, Laczkovics A. Clinical and electrophysiologic correlates of sinus node dysfunction after heart transplantation. Chest 1990;97:890-5.

4 Dibiase A, Tse TM, Schnittger I, Wexler 1, Stinson EB, Valantine HA. Frequency and mechanism of bradycardia in cardiac transplant patients and need for pacemakers. Am ₹ Cardiol 1991;67:1385-9.

5 Scott CD, McComb JM, Dark JH, Bexton RS. Permanent pacing after cardiac transplantation. Br Heart $\mathcal{F} 1993$; 69:399-403.

6 Scott CD, Omar I, McComb JM, Dark JH, Bexton RS. Long-term pacing in heart transplant recipients is usually unnecessary. PACE 1991;14:1792-6.

7 Holt ND, Tynan MM, Scott CD, Parry G, Dark JH, McComb JM. Permanent pacemaker use after cardiac transplantation: completing the audit cycle. Heart 1996; 76:435-8.

8 Report of a working party of the British Pacing and Electrophysiology Group. Recommendations for pacemaker prescription for symptomatic bradycardias. $\mathrm{Br}$ Heart f 1991;66:185-91.

9 Ray SG, Griffith MJ, Jamieson S, Bexton RS, Gold RG. Impact of the recommendations of the British Pacing and Electrophysiology Group on pacemaker prescription and on the immediate costs of pacing in the Nothern region. on the immediate costs of

10 Mounsey JP, Ray SG, Griffith MJ, Gold RG, Bexton RS. Impact of internal audit on pacemaker prescription and the immediate costs of pacing in the Nothern region: towards implementation of the recommendations of the British Pacing and Electrophysiology Group. Br Heart $\mathcal{F}$ 1994;71:395-8.

11 Parry G, Malbut K, Dark JH, Bexton RS. Optimal pacing modes after cardiac transplantation: is synchronisation of recipient and donor atria beneficial? Br Heart 7 1992;68: 195-8.

12 Scott CD, Dark JH, McComb JM. Evolution of the chronotropic response to exercise following cardiac transplantation. Am $\mathcal{F}$ Cardiol 1995;76:1292-6. 